\title{
NOVAS REFLEXÕES SOBRE A INTERNACIONALIZAÇÃO DAS EMPRESAS BRASILEIRAS
}

\author{
Diego Bonaldo Coelho \\ Professor do Centro de Ciências Sociais Aplicadas, Universidade Presbiteriana Mackenzie - São Paulo - SP, Brasil \\ diego.coelho@mackenzie.br
}

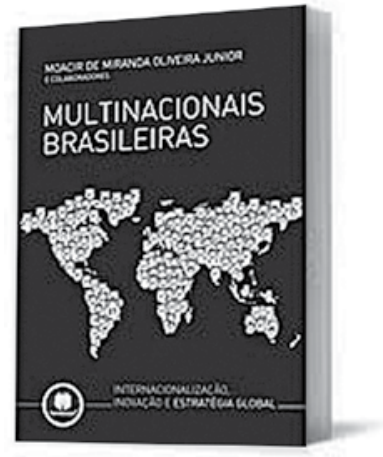

\section{MULTINACIONAIS BRASILEIRAS: INTERNACIONALIZACÃO, INOVACÃO E ESTRATÉGIA GLOBAL}

De Moacir de Miranda Oliveira Junior e colaboradores. Porto Alegre: Bookman, 2010. 358 p.

O surgimento e a consolidação da economia global instauraram nova ordem e dinâmica da competição empresarial, demandando das empresas a formulação de inovadoras estratégias de crescimento e expansão, quando não da mera luta pela sobrevivência. Na esteira dessa nova economia, a procura por outros mercados e a internacionalização da produção emergem como estratégias dominantes, pelas quais as empresas têm busca- do, via atuação internacional, diversificar e penetrar mercados, acessar recursos mais baratos, obter ganhos de escala e estabelecer relações mais próximas com parceiros produtivos e tecnológicos, tudo com a expectativa de aumentar a competitividade.

A movimentação das empresas desde as últimas décadas do século XX corrobora a opção por essas estratégias, facilmente observadas por meio de quatro aspectos inter-relacionados, conforme atestam autores seminais como Castells, Dicken e Dunning: i) crescimento substancial do comércio internacional; ii) aumento do investimento direto estrangeiro; iii) papel central das empresas internacionalizadas como produtoras na economia global; e iv) formação de redes internacionais de produção.

Constata-se, nesse cenário, que nova geografia e especialização da produção ocorrem na economia global, sendo seus principais atores as empresas internacionalizadas, as quais, pelo processo de inserção comercial e produtiva, acabam por reconfigurar substancialmente a dinâmica de alocação de recursos, bem como os paradigmas da Administração, da gestão de ativos e das arquiteturas inter e intraorganizacionais.

Entretanto, se o fenômeno da internacionalização das empresas é amplamente perceptível, seu entendimento, determinantes e fundamentos ainda são campos abertos a debates, não sendo consensuais. O imbróglio analítico reside em dois pontos específicos: primeiramente, a relativa novidade do fenômeno, e, secundariamente, questões históricas, conjunturais e estruturais, dado que o processo de internacionalização não se iniciou de maneira homogênea e simultânea, mas em dinâmicas, padrões, momentos e países diferentes.

Tais questões podem ser observadas no mainstream acadêmico, no qual toda a construção de modelos teóricos e análises desse fenômeno e de seus impactos partem, naturalmente, das empresas dos países tidos como centrais, destacadamente os Estados Unidos, os quais a literatura convencionou chamar de primeiros entrantes. Por outro lado, o contexto contemporâneo revela que a estratégia de internacionalização não se trata mais de fenômeno exclusivo do Norte. Há recente e crescente participação das empresas do hemisfério Sul e dos emergentes. A sigla BRIC (Brasil, Rússia, Índia e China), já disseminada senso comum afora, somada a certo reordenamento dos fluxos comerciais, de investimento e financeiros, sinaliza que atualmente novos players, tratados como entrantes tardios, estão ativamente surgindo, com suas dinâmicas e características específicas.

Dessa maneira, não é ocioso ressaltar que o contexto atual urge pesquisas 
e reflexões acadêmicas que não apenas foquem esses países emergentes, mas que releiam e reformulem as rázes e os modelos teóricos nórdicos e norte-americanos de análise e interpretação do fenômeno da internacionalização, seus padrões, determinantes e dinâmicas, contextualizando-os nesses países.

Tal desafio coloca-se prioritariamente ao Brasil, dado que analisar a sua economia e suas empresas nunca foi tarefa fácil. Entender os meandros de uma dinâmica econômica tão peculiar como a brasileira, bem como as singularidades da gestão de suas empresas, apresenta diversos caminhos, assim como grandes dificuldades. Ao se contextualizar essa empreitada na área de Negócios Internacionais, o desafio ganha maiores proporções e complexidade, uma vez que une, indissociavelmente, tanto os aspectos econômicos como os empresariais.

$\mathrm{Na}$ busca por preencher essa lacuna e explorar os pormenores desse fenômeno no Brasil, importantes obras nacionais vêm sendo lançadas recentemente na área de Administração, como as de Fleury e Fleury, Tanure e Duarte e Ramsey e Almeida. Na esteira da empreitada desses pioneiros autores, Moacir de Miranda Oliveira Junior e colaboradores apresentam Multinacionais brasileiras: internacionalização, inovação e estratégia global, obra recém-lançada sobre a formação e consolidação da internacionalização das empresas brasileiras.

Com esse livro, Oliveira Junior colabora para a Administração brasileira com qualidade, dada a maneira como aborda o tema, destacadamente na forma como compõe sua obra, que carrega importante contribuição acadêmica, com a vantagem de estendêla ao meio empresarial.

Organizado por meio da coletânea de 18 capítulos, Multinacionais brasileiras apresenta os resultados de profundas pesquisas acadêmicas de vários especialistas, redigidos em linguagem acessível, afastando-se do rebuscado academicismo, sem cair, todavia, na fácil prescrição do mundo empresarial.

A obra divide-se tematicamente em quatro partes que contemplam as principais questões e dimensões pertinentes ao fenômeno de internacionalização das empresas brasileiras e do surgimento de suas multinacionais.

Em sua primeira parte, Internacionalização: modelos teóricos e dimensões teóricas, prepara-se o terreno para a análise do surgimento das multinacionais brasileiras e de suas estratégias, abordando as principais dimensões teóricas pertinentes à internacionalização. Temas como a evolução dos Negócios e Gestão Internacionais, assim como estas áreas tratam o fenômeno da internacionalização, são dissertados com relativa profundidade.

$\mathrm{Na}$ segunda parte, Estratégia e desafios paras as multinacionais brasileiras, apresenta-se a mais recente e bem-acabada análise da internacionalização das empresas brasileiras. Formado majoritariamente por capítulos elaborados com base em surveys realizados com empresas brasileiras de vários setores, a presente parte não apenas mapeia a internacionalização das empresas brasileiras, como também analisa suas performances e estratégias de inserção internacional adotadas, levandose em consideração determinantes como recursos, instituições, barreiras, relações de trabalho, entre outros.

A penúltima parte, Inovação e gestão do conhecimento em multinacionais brasileiras, sustenta-se em aprofundados estudos de casos com empresas âncoras brasileiras, como Embraer, Odebrecht, Gerdau, Petrobras e Natura, para analisar como a inovação em valor e a transferência e gestão do conhecimento têm se manifestado e vêm sendo incorporadas pelas empresas brasileiras em suas estratégias de internacionalização, evidenciando os principais diferenciais, assim como desafios.

Por fim, o livro encerra-se com a quarta parte, Reconstruindo a cadeia de valor: offshoring, redes e consórcios, na qual se discutem novos modelos de negócios e de associação de empresas para incrementar e potencializar a internacionalização das empresas brasileiras, principalmente as de micro, pequeno e médio portes.

Ao final da leitura, endossa-se que Multinacionais brasileiras contribui consideravelmente para aprofundar e ampliar o debate e reflexão sobre a internacionalização das empresas brasileiras, dadas suas ricas pesquisas empíricas que conseguem registrar questões recentes, peculiares e pertinentes do surgimento das multinacionais brasileiras. Entretanto, como se nota nessa e nas demais obras da área, ainda há muitas lacunas a serem superadas, principalmente as de caráter teórico. Como em Multinacionais brasileiras, as análises brasileiras ainda tendem a apenas replicarem, em maior ou menor grau, as teorias nórdicas de internacionalização, principalmente, sem necessariamente partirem de um esforço crítico para se elaborar uma releitura teórica dessas bases, que sugira abordagens multidimensionais e contextualizadas. Dessa maneira, os referenciais teóricos parecem dados em quase toda a produção, como se fossem estanques, não passíveis de crítica. Em alguns capítulos da presente obra, por exemplo, parece-se ler o mesmo texto, dada a maneira insípida com que se tratam a teoria e modelos nórdicos.

Coloca-se, então, pela frente, o desafio de elaborar trabalhos que entendam o contexto não apenas quanto aos casos que se estudam, mas, também, aos seus modelos teóricos, a fim de melhorarmos seu poder analítico, principalmente em internacionalização. 